\title{
13-Acetoxysarcocrassolide Induces Apoptosis on Human Gastric Carcinoma Cells Through Mitochondria-Related Apoptotic Pathways: p38/JNK Activation and PI3K/AKT Suppression
}

\section{Ching-Chyuan Su ${ }^{1,2}$, Jeff Yi-Fu Chen ${ }^{3}$, Zhong-Hao Din ${ }^{4}$, Jui-Hsin Su ${ }^{5}$, Zih-Yan Yang ${ }^{6}$, Yi-Jen}

Chen ${ }^{7}$, Robert Y.L. Wang ${ }^{8, \dagger}, *$ and Yu-Jen Wu ${ }^{2, \dagger, *}$

1 Antai Medical Care Cooperation Antai Tian-Sheng Memorial Hospital, Pingtung 92842, Taiwan; E-Mail: a081001@mail.tsmh.org.tw

2 Department of Beauty Science, Meiho University, Pingtung 91202, Taiwan

3 Department of Biotechnology, Kaohsiung Medical University, Kaohsiung, Taiwan; E-Mail: yifuc@kmu.edu.tw

4 Graduate Institute of Applied Healthy and Biotechnology, Meiho University, Pingtung 91202, Taiwan; E-Mail: nmm10023@yahoo.com.tw

5 National Museum of Marine Biology and Aquarium, Pingtung 94446, Taiwan; E-Mail: x2219@nmmba.gov.tw

6 Graduate Institute of Food Science, National Pingtung University of Science and Technology, Pingtung 91202, Taiwan; E-Mail: vian10045@gmail.com

7 Department of Physical Medicine and Rehabilitation, Kaohsiung Medical University Hospital, Kaohsiung, Taiwan; E-Mail: chernkmu@gmail.com

8 Department of Biomedical Sciences and Research Center for Emerging Viral Infections, College of Medicine, Chang Gung University, Taoyuan 33302, Taiwan

$\dagger$ The authors contributed equally to this work.

* Author to whom correspondence should be addressed; E-Mails: wyr924@ms24.hinet.net (Y.-J.W.); yuwang@mail.cgu.edu.tw (R.Y.W.); Tel.: +886-8-779-9821 (ext. 8613) (Y.-J.W.);

Fax: +886-8-779-7821 (Y.-J.W.).

External Editor: Peer B. Jacobson

Received: 18 September 2014; in revised form: 15 October 2014 / Accepted: 20 October 2014 / Published: 23 October 2014

Abstract: 13-acetoxysarcocrassolide (13-AC), an active compound isolated from cultured Formosa soft coral Sarcophyton crassocaule, was found to possess anti-proliferative and 
apoptosis-inducing activities against AGS (human gastric adenocarcinoma cells) gastric carcinoma cells. The anti-tumor effects of 13-AC were determined by MTT assay, colony formation assessment, cell wound-healing assay, TUNEL/4,6-Diamidino-2-phenylindole (DAPI) staining, Annexin V-fluorescein isothiocyanate/propidium iodide (PI) staining and flow cytometry. 13-AC inhibited the growth and migration of gastric carcinoma cells in a dose-dependent manner and induced both early and late apoptosis as assessed by flow cytometer analysis. 13-AC-induced apoptosis was confirmed through observation of a change in $\Delta \Psi \mathrm{m}$, up-regulated expression levels of Bax and Bad proteins, down-regulated expression levels of Bcl-2, Bcl-xl and Mcl-1 proteins, and the activation of caspase-3, caspase-9, p38 and JNK. Furthermore, inhibition of p38 and JNK activity by pretreatment with SB03580 (a p38-specific inhibitor) and SP600125 (a JNK-specific inhibitor) led to rescue of the cell cytotoxicity of 13-AC-treated AGS cells, indicating that the p38 and the JNK pathways are also involved in the 13-AC-induced cell apoptosis. Together, these results suggest that 13-AC induces cell apoptosis against gastric cancer cells through triggering of the mitochondrial-dependent apoptotic pathway as well as activation of the p38 and JNK pathways.

Keywords: 13-acetoxysarcocrassolide; soft coral; gastric cancer cells; apoptosis; p38 and JNK pathways

\section{Introduction}

Gastric cancer (GC), a gastrointestinal cancer, is ranked as the second most common cause of cancer-related death in the world [1,2]. It has been reported that estimates of nearly one hundred thousand new cases of gastric cancer have occurred each year since 2010 [3]. The incidence of gastric cancer in East Asia is much higher than that in other regions [4]. Many studies have revealed that the high mortality rate of gastric cancer is related to the lack of an effective therapy for advanced stages of the disease. Many conventional therapy options have been developed for the treatment of gastric cancer, including surgery, chemo- and radiation therapy and combination treatments. The most effective medical treatment is surgical removal of the tumor in the early stages [5]. However, because of occult symptoms in the early stages of gastric cancer, most patients are not diagnosed until the cancer has progressed to an advanced stage. In addition, tumors will recur in many patients receiving surgical resection, leading to short survival durations. The 5-year survival rate has remained at around $20 \%-25 \%$ in the Western world [6,7]. The high mortality rate emphasizes the need for effective medical treatments for patients with advanced stages of gastric cancer [8]. The risk factors for the development of GC are atrophic gastritis, helicobacter pylori infection, intestinal metaplasia, smoking and genetic differences [9]. Although several new drugs, including taxane paclitaxel, platinum derivative oxaliplatin, and the topoiosmerase-I inhibitor irinotecan, have led to a better prognosis for patients with advanced gastric cancer, the response rate is only $20 \%-40 \%$ [10]. Therefore, it is essential to find new treatments for gastric cancer. 
Several new therapeutic applications of natural products obtained from soft coral have been widely investigated for the treatment of different types of cancer [11-13]. Some chemical compounds isolated from marine soft corals, such as diterphenoids, diterpenes, and prostanoids, have been reported to exert various biological activities, including anti-proliferation, anti-migratory, and apoptosis induction effects, on different cancer cell lines, such as prostate cancer cells, hepatocellular carcinoma, breast cancer cells, colon cancer cells, cervix cancer cells, oral squamous cell, bladder cancer cells and melanoma cells [14-20]. Soft corals have therefore emerged as one of the most prolific sources of natural products with novel activities and antitumor effects.

When cells are attacked by pathogens, cellular apoptosis can serve as a guard against pathogens and regulate the cell death process during tissue development, in addition to maintaining homeostasis [19,21]. Cells trigger the apoptosis event through the plasma membrane (extrinsic pathways) and/or within cells (intrinsic pathways) [22]. The initiation of intrinsic pathways is caused by the stimulation of biochemical events, resulting in the organelles inside the cells experiencing enhanced intracellular stresses. In this pathway, mitochondria and the endoplasmic reticulum (ER) play important roles in the execution of apoptosis [23,24]. Mitochondria are organelles that participate in energy conversion and play important roles in many cellular functions, including calcium buffering, regulation of signal cascades, and apoptosis regulation. Dysfunction of mitochondria has been found to be the major event during cellular apoptosis. Bcl-2 protein, the pro-apoptotic gene, participates in forming pores and causing a permeable membrane, leading to the release of cytochrome C protein [25]. The cytochrome $\mathrm{C}$ protein then activates caspase- 9 as well as the downstream effector caspase-3, subsequently cleaving poly (ADP-ribose) polymerase-1 (PARP-1), inducing chromatin condensation and DNA chromatin fragmentation [26]. ER is another important cellular homeostasis principal site, as it regulates protein synthesis, protein folding and intracellular calcium levels [27]. The unfolded protein response (UPR) is a cellular stress response related to ER stress. If the ER stress becomes prolonged and severe, it will ultimately lead to apoptosis [28,29]. Three major transducers mediate this response: PKR-like ER-associated kinase (PERK), activating transcription factor 6 (ATF6), and inositol-requiring enzyme-1 (IRE1) [30,31].

It is important to explore new effective anticancer drugs and develop therapies against gastric cancer. In this study, 13-acetoxysarcocrassolide (13-AC) was isolated from cultured Formosa Sarcophyton crassocaule and the cytotoxic effect on gastric carcinoma AGS cells was subsequently examined. 13-AC possessed anti-proliferative, anti-migratory and apoptosis-inducing activities against AGS cells. The results showed that apoptosis was induced by 13-AC through the mitochondrial-dependent apoptotic pathway with p38 and JNK activation. These results provide useful information regarding the biochemical aspects of the cytotoxic effects of 13-AC on AGS cells and will accelerate drug development and improve the monitoring of human gastric carcinoma.

\section{Results}

\subsection{The Cytotoxic Effects of 13-AC on AGS Gastric Carcinoma Cells}

To explore the potential cytotoxic effect of 13-AC on AGS cells, MTT assays, cell morphology assessments, colony formation assays and wound-healing assays were performed. As expected, 13-AC 
treatment clearly reduced the cell viability of AGS cells in a dose-dependent manner in comparison with the mock control (Figure 1A). Note that a significant reduction (greater than $36 \%$ ) in cell viability was observed in the 13-AC-treated cells at the final concentration of $20 \mu \mathrm{M}$. Next, the cell morphology was investigated using inverted light microscopy. As shown in Figure 1B, the 13-AC-treated AGS cells reduced in size, and a distinct decrease in the cell population was observed in comparison with the mock-treated cells, revealing that 13-AC induces cell apoptosis (Figure 1B). We then tested the colony-forming ability of the 13-AC-treated AGS cells. The results showed a significant decrease in colony formation upon 13-AC treatment. Treatment with 5, 10, 15 and $20 \mu \mathrm{M}$ of $13-\mathrm{AC}$ dose-dependently reduced colony formation, the reduction rates being approximately $5 \%, 10 \%, 31 \%$ and $78 \%$, respectively (Figure 1C), indicating the effect of $13-\mathrm{AC}$ on the reduction of colony formation. As the behavior of cancer cell migration is one of the critical processes in the development of programmed cell death, we then evaluated the effect of 13-AC on AGS cell migration using wound-healing assays. The results of the wound-healing migration assays showed that 13-AC treatment led to reduced wound closure in a dose-dependent manner at the 24-hour time point (Figure 1D).

Similarly, two additional gastric cancer cell lines (NCI-N87 and SNU-1) were chosen for treatment with 13-AC at final concentrations of 5, 10 and $15 \mu \mathrm{M}$. The MTT assay results showed that 13-AC treatment of NCIN87 and SNU-1 cells also induced cell cytotoxicity (Supplementary Figure S1). Together, these results implied cell cytotoxic effects of 13-AC on these gastric cancer cells.

\subsection{3-AC Induces Apoptosis of AGS Cells}

In our previous study, 13-AC induced apoptosis in bladder cancer BFTC cells [20]. To investigate whether 13-AC induces apoptosis of AGS cells, an apoptotic assay was employed. First, AGS cells were stained with fluorescein isothiocyanate (FITCH-labelled Annexin V, green fluorescence) and simultaneously with dye exclusion of propidium iodide (PI) for apoptosis flow cytometric detection in early apoptotic cells analyses. The dose-dependent apoptosis rates were $4.13 \%, 15.9 \%$ and $32.1 \%$ when treated with 13-AC at concentrations of 0,10 and $15 \mu \mathrm{M}$, respectively (Figure 2A). These results clearly indicated that 13-AC efficiently induced early apoptosis of AGS cells. Second, TUNEL/DAPI staining and Annexin V-FITC/PI double staining were employed to further validate the apoptotic effect of 13-AC on AGS cells. Some massive apoptotic bodies were observed in AGS cells treated with 10 $\mu \mathrm{M}$ and $15 \mu \mathrm{M}$ of 13-AC (Figure 2B,C). In contrast, there was neither positive staining with TUNEL/DAPI nor Annexin V-FITC/PI staining in the mock-treated AGS cells. Together, these results demonstrated that treatment with 13-AC significantly induced early apoptosis of AGS cells, and this apoptotic effect was exerted in a dose-dependent manner. 
Figure 1. Evaluation of the anti-proliferative and anti-migratory effects of 13-AC on AGS cells (human gastric adenocarcinoma cells). (A) The AGS cell viability was suppressed in a dose-dependent manner upon treatment with 13-AC. AGS cells were treated without or with 13-AC at final concentrations between $2.5 \mu \mathrm{M}$ and $20 \mu \mathrm{M}$ for $24 \mathrm{~h}$. The cells were then harvested for MTT assay as described in the Materials and Methods section. The data shown are representative of three independent experimental results $(* p<0.001)$. (B) The morphological changes of AGS cells upon 13-AC treatment. AGS cells were treated with 5, 10,15 and $20 \mu \mathrm{M}$ of 13-AC for $24 \mathrm{~h}$. The morphology of the cells was observed using inverted light microscopy. Scale bars $=20 \mu \mathrm{m}$. (C) Colony formation assay for AGS cells. AGS cells were treated with various concentrations of 13-AC $(5,10$ and $20 \mu \mathrm{M})$, followed by a colony formation experiment, as described in the Materials and Methods section. The decreased number of colonies indicated dose-dependent inhibition of AGS cells colony formation upon treatment with 13-AC (* $p<0.001)$. (D) Inhibition of AGS cell migration upon treatment with 13-AC. AGS cells were treated with DMSO (control) or 13-AC at a final concentration of $15 \mu \mathrm{M}$, followed by examination of cell migration using the cell migration assay as described in the Materials and Methods section. The image was obtained under $100 \times$ magnification.

A
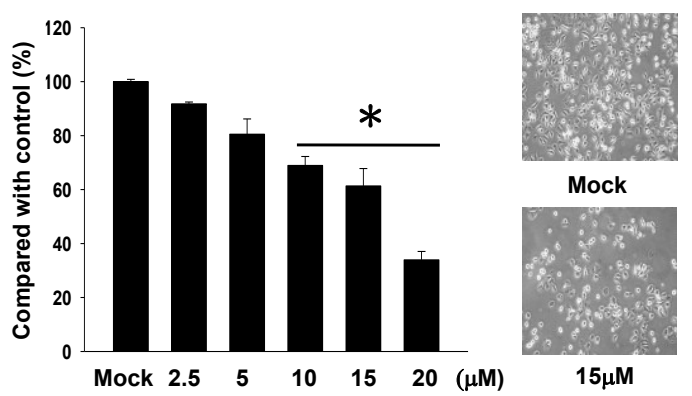

$$
\text { Mock }
$$

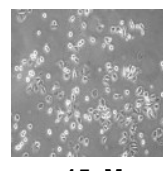

$15 \mu \mathrm{M}$

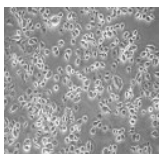

$5 \mu \mathrm{M}$

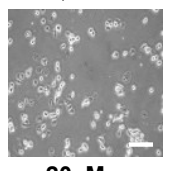

$20 \mu M$

\section{C}
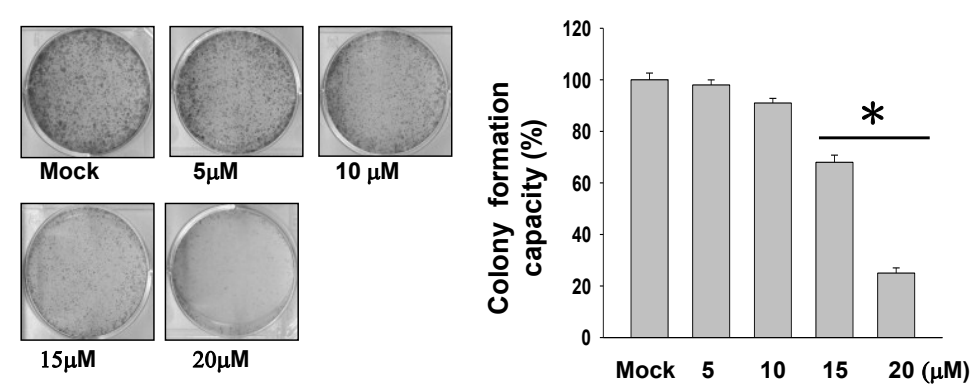

D

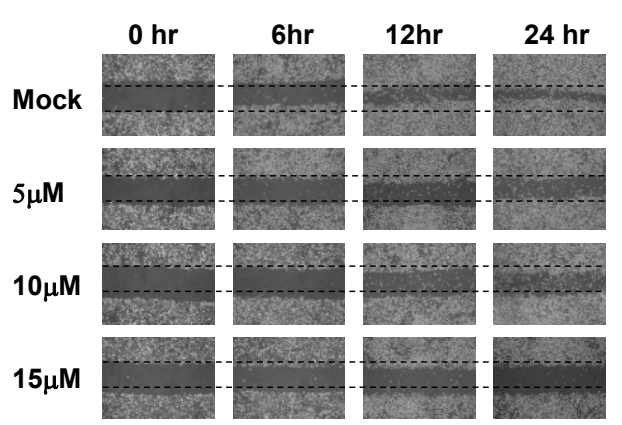


Figure 2. The appearance of apoptosis characteristics in 13-AC-treated AGS cells. (A) Detection of apoptotic AGS cells after 10 and $15 \mu \mathrm{M}$ 13-AC treatment using Annexin V-FITC/PI analysis. Note that early apoptotic cells were increased after 10 and $15 \mu \mathrm{M}$ 13-AC treatment. (B) Detection of apoptotic AGS cells by TUNEL and DAPI staining assay. AGS cells were treated with DMSO or 13-AC at final concentrations of 10 and $15 \mu \mathrm{M}$ for 24 $\mathrm{h}$ and then observed using a fluorescent microscope. Scale bar $=50 \mu \mathrm{m}$. (C) Annexin V-FITC and PI analyses of apoptotic AGS cells upon 13-AC treatment. AGS cells were stained with Annexin-V (green) as well as PI (red) after 10 and $15 \mu \mathrm{M}$ 13-AC treatment. Scale bar $=50 \mu \mathrm{m}$.
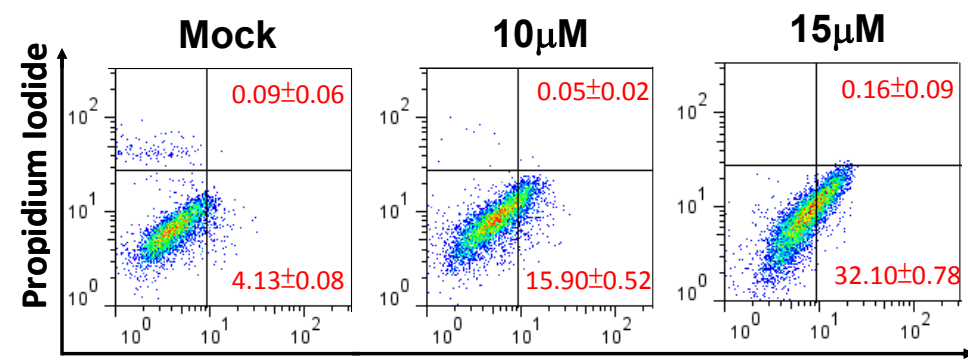

Annexin V-FITC

B
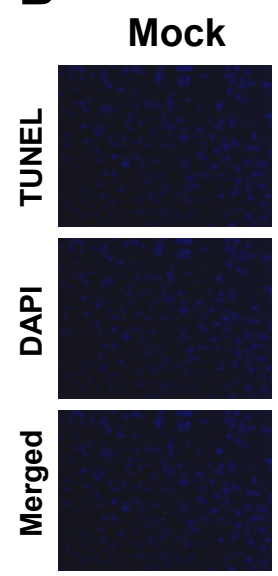

$10 \mu \mathrm{M}$
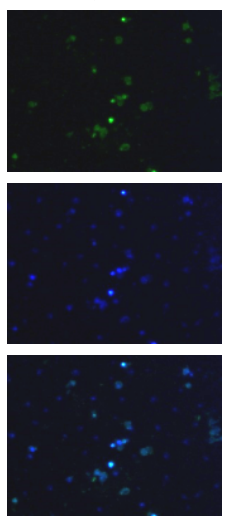

$15 \mu \mathrm{M}$
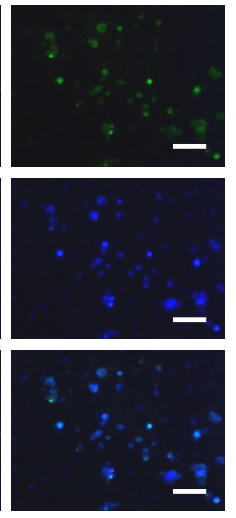

C
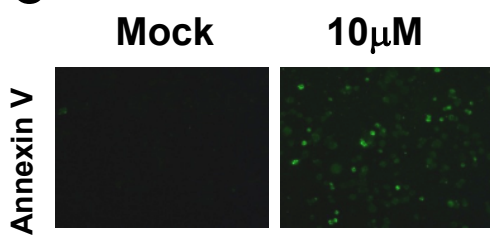

$15 \mu \mathrm{M}$
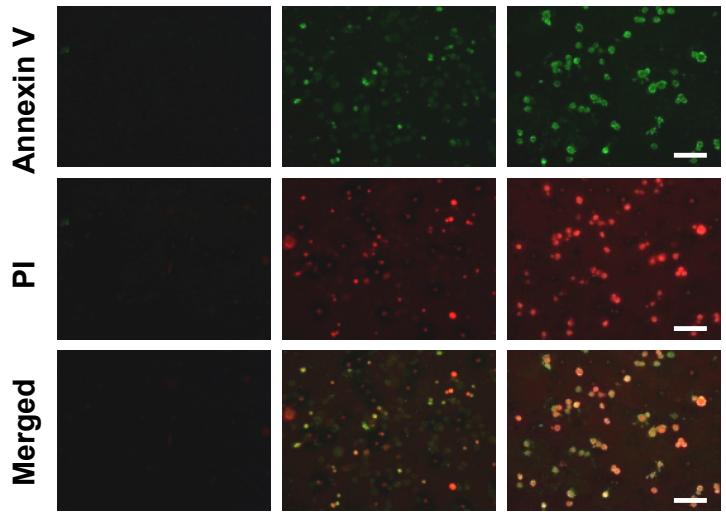

\subsection{3-AC Induces Apoptosis and Causes a Mitochondria Membrane Potential Change in AGS Cells}

As the change in the mitochondrial membrane potential $(\Delta \Psi \mathrm{m})$ is well-defined as a role involving in initiation of mitochondrial-related apoptosis, we measured the change in $\Delta \Psi \mathrm{m}$ induced by $13-\mathrm{AC}$ using JC-1 dye. As a result, fluorescence microscopy showed significantly reduced red fluorescence signals (JC-1 aggregation) and increased green fluorescence signals (JC-1 monomer) in the 13-AC-treated AGS cells, suggesting a loss of $\Delta \Psi \mathrm{m}$ upon 13-AC treatment (Figure $3 \mathrm{~A}$ ). Next, we explored the potential mechanism of 13-AC-induced apoptosis in AGS cells. To address this issue, several mitochondrial-related apoptotic proteins, including Bcl-2, Bcl-xl, Mcl-1, Bad, p-Bad, Bax, Bid and cytosolic cytochrome $\mathrm{C}$, were investigated by western blotting using specific antibodies as indicated. The expression levels of Bax, Bad and cytosolic cytochrome $\mathrm{C}$ were significantly increased in a dose-dependent manner in the 13-AC-treated AGS cells. In contrast, the expression levels of Bcl-2, Bcl-xl, Mcl-1, and p-Bad were decreased upon 13-AC treatment (Figure 3B). It has been 
reported that gene members of the Bcl-2 family regulate the mitochondrial cell death pathway; in particular, the stoichiometries of Bax (pro-apoptotic gene) and Bcl-2 (anti-apoptotic gene) are important for cytochrome $\mathrm{C}$ release as well as the following downstream activation of caspase protein. In this study, increased expression levels of Bax and cytochrome $\mathrm{C}$ were detected in the 13-AC-treated cells, implying that the 13-AC-induced apoptosis was associated with activation of the mitochondrial-related pathway in AGS cells. Furthermore, three different mitochondrial permeability transition inhibitors (aristolochic acid; ArA, cyclosporine A; CyA and trifluoperazine; TFZ) were used for treatment prior to treatment with 13-AC in AGS cells. As expected, these inhibitors inhibited the 13-AC-induced cell apoptosis (Figure 3C). In addition, several mitochondrial-related apoptotic proteins, including cytosolic cytochrome $\mathrm{C}, \mathrm{Bax}, \mathrm{Bcl}-2$ and $\mathrm{Bcl}-\mathrm{xl}$ proteins, were detected by western blotting. The expression levels of Bcl-2 and Bcl-xl were increased in the 13-AC-treated cells when the cells were pretreated with CyA, ArA and TFZ. In contrast, the expression levels of Bax and cytosolic cytochrome $\mathrm{C}$ were decreased in the 13-AC-treated cells when the cells were pretreated with CyA, ArA and TFZ (Figure 3D). Taken together, these results indicated that mitochondria dysfunction-mediated apoptosis was involved in 13-AC-induced cell apoptosis.

\subsection{3-AC Activates the Caspase-Dependent Pathway Causing Cell Apoptosis in AGS Cells}

Caspase, another kinase protein that plays an important role in the regulation of cell apoptosis, was investigated in addition to three mitochondrial-related apoptosis proteins as described above [20,32]. It is believed that activation of both caspase- 3 and caspase- 9 stimulates mitochondrial cell death signals [33]. In this study, we further investigated the effects of 13-AC on the activation of caspase-3, caspase-9 and PARP cleavage by western blotting using specific antibodies as shown in the Materials and Methods section. In Figure 4A, the western blotting results show up-regulated expression levels of cleaved-PARP (89 $\mathrm{kDa}$ proteolytic fragments), cleaved-caspase-3 and cleaved-caspased-9 in 13-AC-treated cells. Down-regulated expression levels of pro-caspase-3 and pro-caspase-9 after 13-AC treatment were observed. In addition, 13-AC treatment increased the caspase-3 and caspase- 9 activities (Figure 4B). These results showed that 13-AC could activate the caspase-dependent pathway.

To gain a comprehensive understanding of 13-AC-induced cell apoptosis through caspase activation, cells were pre-treated with either Z-LEHD-FMK (caspase-9 inhibitor) or Z-DEVD-FMK (caspase-3 inhibitor) prior to 13-AC treatment. The results showed that Z-LEHD-FMK and Z-DEVD-FMK significantly inhibited the 13-AC-induced cell apoptosis (Figure 4C). Taken together, these results suggested that both caspase- 3 and caspase- 9 proteins are involved in the 13-AC-induced cell apoptosis in AGS cells. 
Figure 3. 13-AC induces mitochondrial membrane depolarization in AGS cells. (A) Cells were treated as indicated and then stained with JC-1 dye, followed by incubation for $20 \mathrm{~min}$ at $37{ }^{\circ} \mathrm{C}, 5 \% \mathrm{CO}_{2}$. The cells were then imaged under a fluorescence microscope at emission wavelengths of $580 \mathrm{~nm}$ (red, upper panels) and $530 \mathrm{~nm}$ (green, lower panels). Scale bars = $50 \mu \mathrm{m}$. (B) Differential expressions of proteins involved in the mitochondrial function were detected by western blotting. Changes in Bcl-2, Bcl-xl, Mcl-1, Bad, p-Bad, Bax and cytosolic cytochrome $\mathrm{C}$ (cytosolic) were observed in AGS cells treated with various concentrations of 13-AC. (C) Effects of three different mitochondrial permeability transition inhibitors, ArA, CyA and TFZ, on the cell viability upon treatment with 13-AC. The mock- and 13-AC-treated cells were combined with different inhibitors as indicated for $24 \mathrm{~h}$, followed by examination of the cell viability by MTT assay. The data shown are representative of three independent experiments $\left({ }^{\#} p<0.05\right)$. (D) Examination of the differentiated expression levels of mitochondrial-related apoptosis pathway proteins in response to the different inhibitors as indicated in 13-AC treated cells. $\beta$-actin was used as the protein loading control.

A

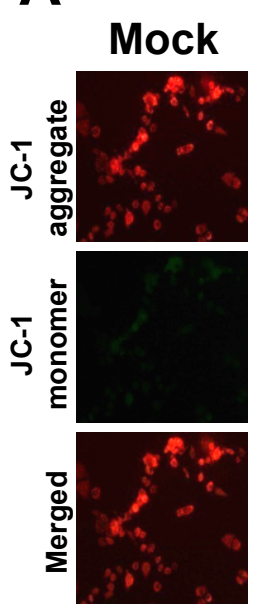

\section{0}
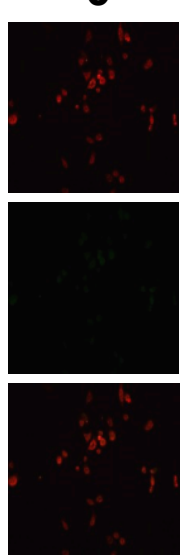
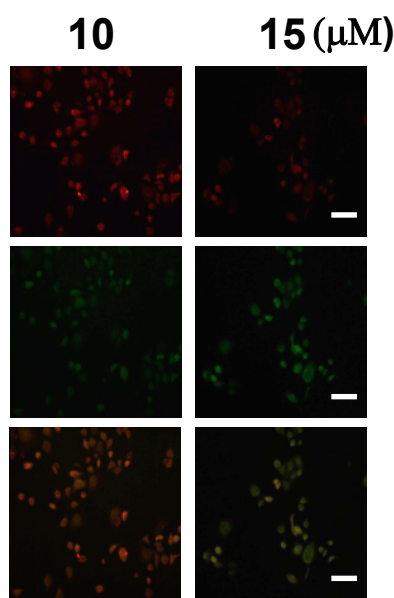

C

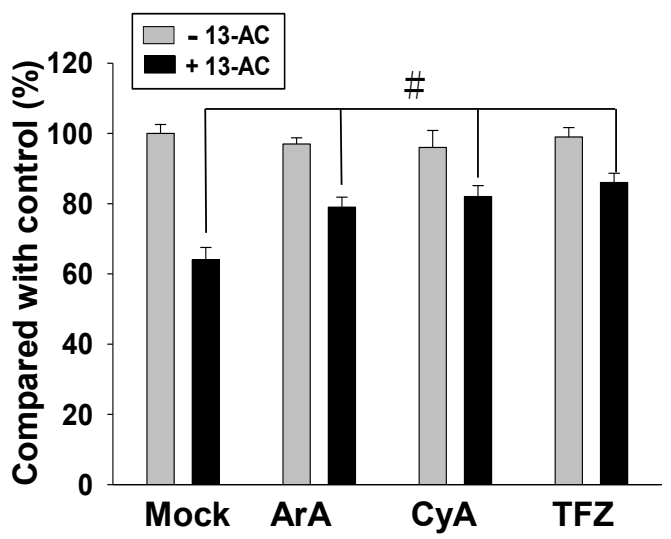

B

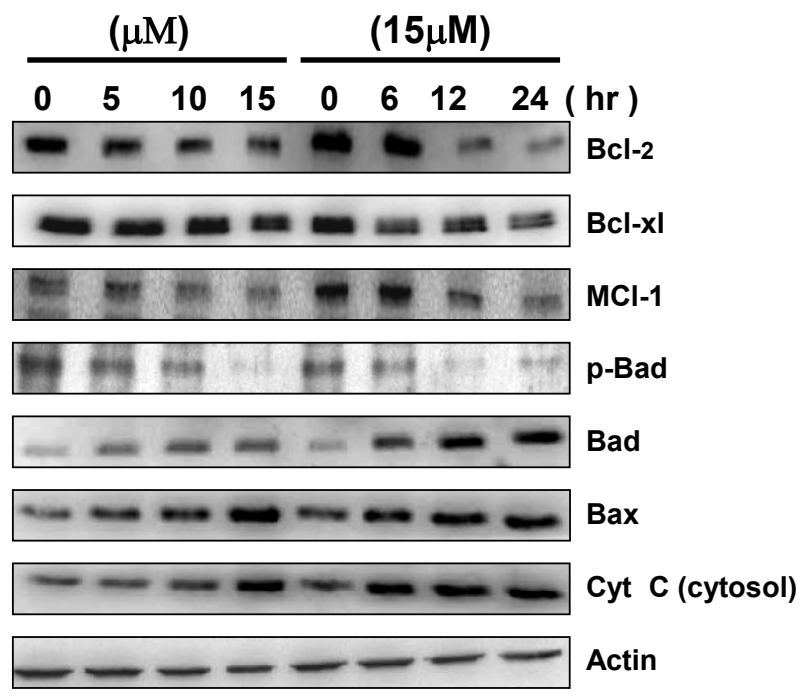

D

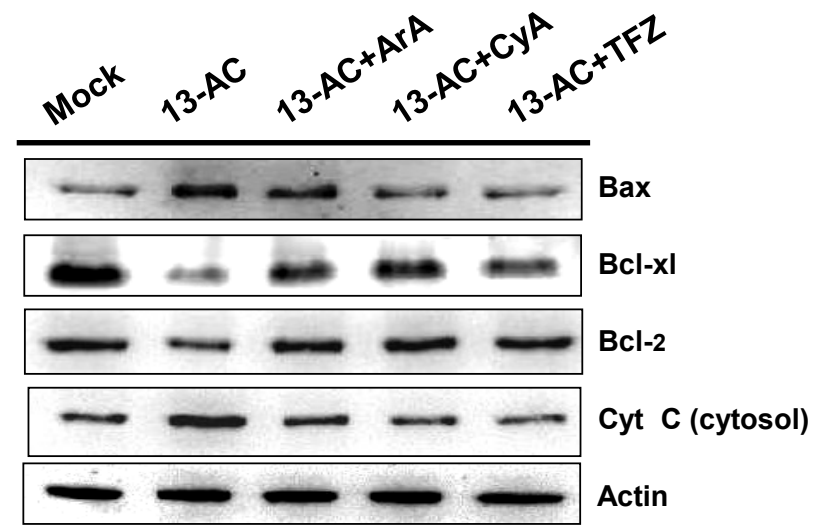


Figure 4. 13-AC induced apoptosis through activation of the caspase cascade pathway. (A) AGS cells were treated with 13-AC either at various concentrations of 0, 5, 10, and $15 \mu \mathrm{M}$ for $24 \mathrm{~h}$ or at the concentration of $15 \mu \mathrm{M}$ for different time periods of 6,12 , and $24 \mathrm{~h}$. The harvested cell lysates were then examined for PARP-1, caspase- 3 and caspase- 9 by western blotting using specific antibodies as indicated. $\beta$-actin was used as the protein loading control. (B) Caspase-3 and caspase-9 activities were increased after 13-AC treatment. The results shown are representative of three independent experiments $\left({ }^{\#} p<0.05\right.$, * $p<0.001$ as compared with the control). (C) Two caspase inhibitors, Z-VAD-FMK (caspase-3 inhibitor) and Z-DEVD-FMK (caspase-9 inhibitor), were added simultaneously with 13-AC to AGS cells. The cells were then harvested and subjected to MTT assay for the evaluation of cell viability. The related cell viabilities were determined from three independent experiments ( ${ }^{*} p<0.05$ as compared with the control). (D) Examination of protein levels for some mitochondrial-related apoptotic proteins, including Bcl-2, Bcl-xl, Bax and Bad proteins. The mock- and 13-AC-treated cell lysates were harvested and subjected to western blot analyses using specific antibodies as indicated.

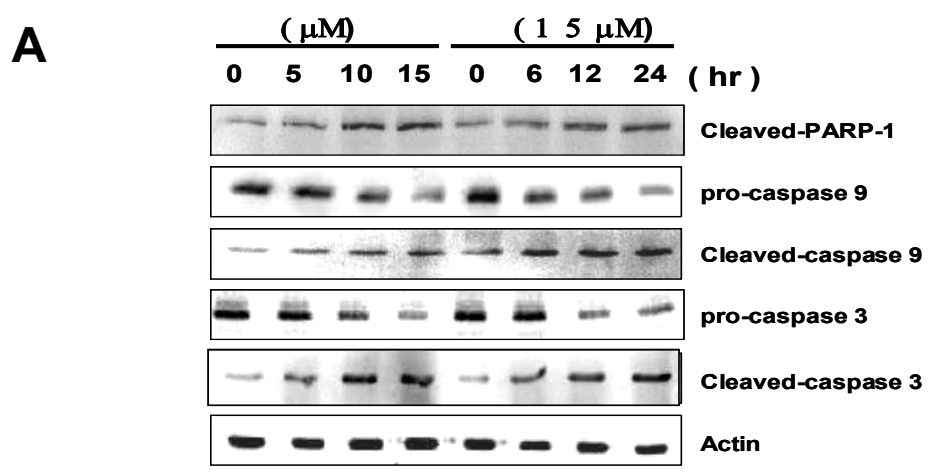

B
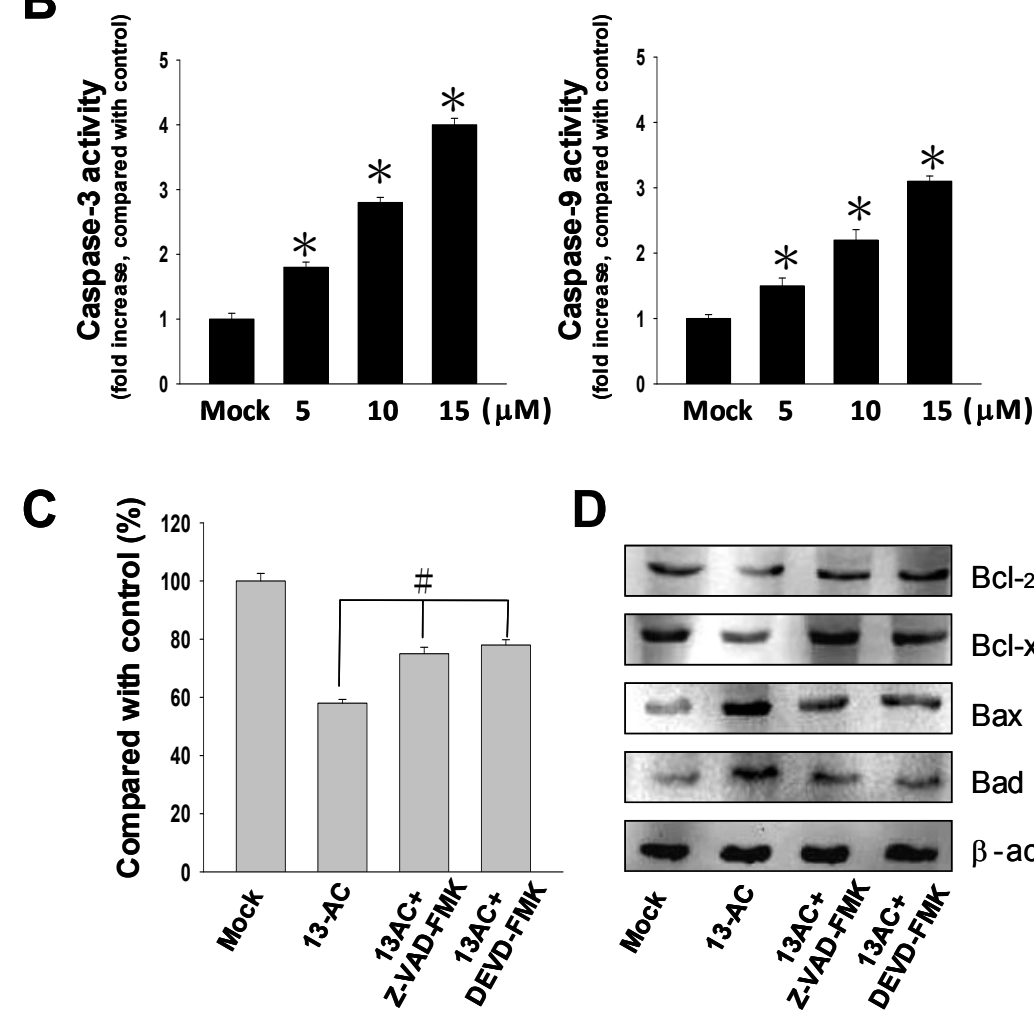

D

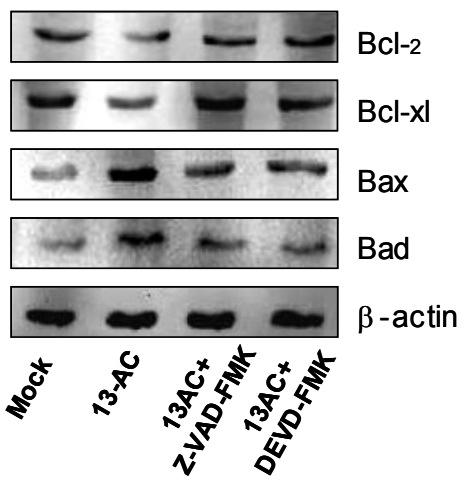




\subsection{3-AC Induces Activation of the $p 38$ and JNK Pathways and Suppression of PI3K/AKT}

Mitogen-activated protein kinases (MAPKs) signal pathways have been demonstrated to play important roles in various biological processes, such as cell proliferation, differentiation and apoptosis [34,35]. Herein, we examined the expression levels of proteins involved in the MAPKs signal pathways in order to investigate the potential effects of 13-AC-induced apoptosis through activation of the MAPKs signaling pathways. As shown in Figure 5, the protein expressions of phosphorylated p38 and JNK were significantly activated in a dose- and time-dependent manner. In contrast, the expression levels of non-phosphorylated AKT, ERK, JNK and p38 were not changed upon 13-AC treatment, nor for treatment with $15 \mu \mathrm{M}$ of $13-\mathrm{AC}$ for various durations. Moreover, down-regulated expression levels of phosphorylated forms of PI3K, AKT and ERK1/2 proteins were also observed in 13-AC-treated cells in both dose- and time-dependent manners. In addition, the expression levels of p53 and p-ATF2 were also up-regulated upon 13-AC treatment.

Figure 5. Effects of 13-AC on the cytotoxicity of AGS cells through MAPK pathway-related proteins. AGS cells were treated with 13-AC at various concentrations of $0,5,10$, and $15 \mu \mathrm{M}$ for $24 \mathrm{~h}$ or treated with $13-\mathrm{AC}$ at the concentration of $15 \mu \mathrm{M}$ for 6,12 , and $24 \mathrm{~h}$. The cells were then harvested and subsequently analyzed for the differential expression levels of proteins by western blotting. $\beta$-actin was used as the protein loading control.

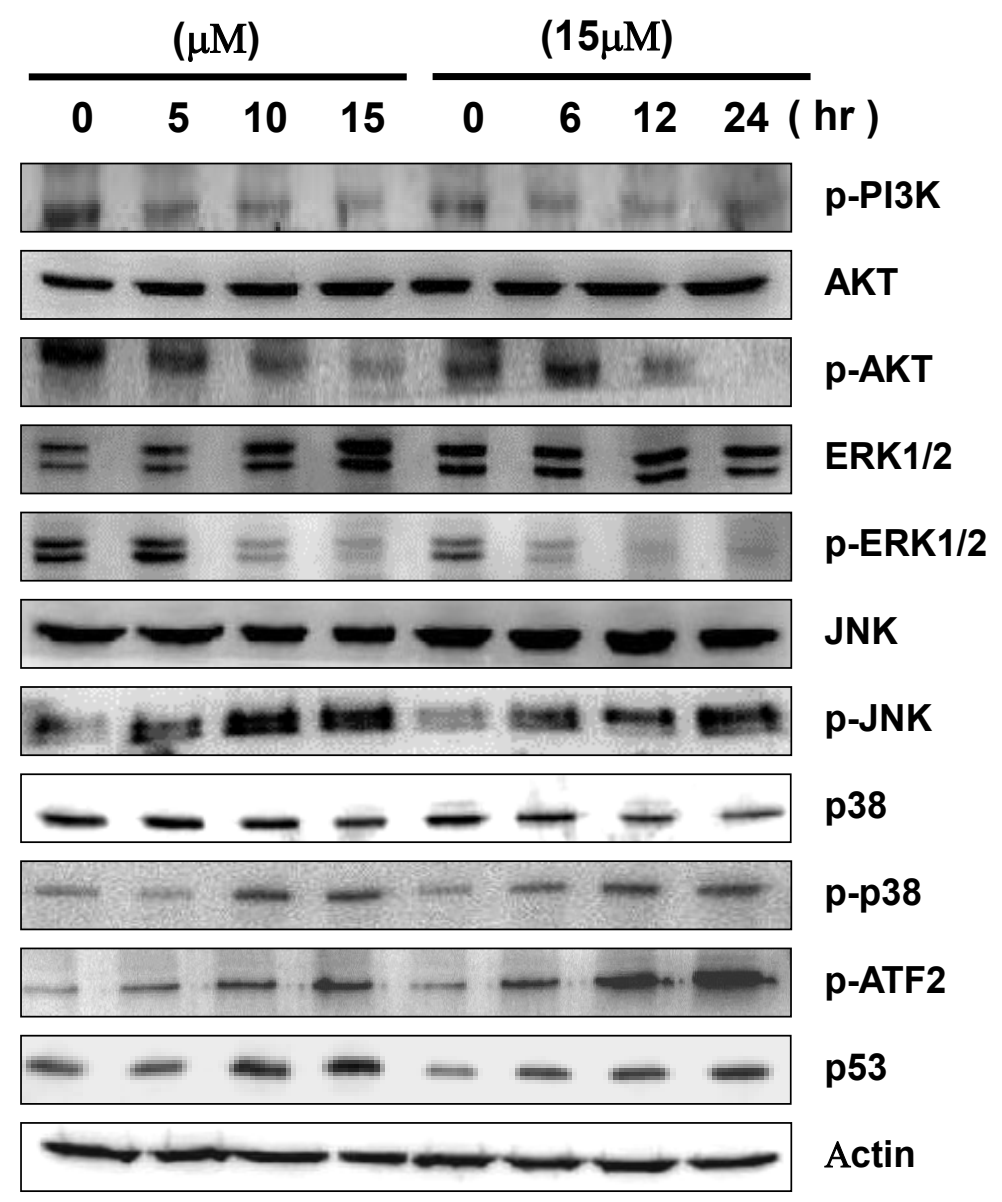


Figure 6. Inhibition of $\mathrm{p} 38$ and JNK activities rescued the cell cytotoxicity of AGS cells caused by 13-AC. (A) Two inhibitors, SB203580 (p38-specific inhibitor) and SP600125 (JNK-specific inhibitor), were added to AGS cells treated with 13-AC and the cell viability was detected by MTT assay as described above. An increased cell viability of the 13-AC-treated AGS cells was observed following addition of SB203580 and SP600125, but not PD98059. The results shown are representative of three independent experiments ( ${ }^{\#} p<0.05$ as compared with the control). (B) Validation of the expression levels of mitochondrial-related proteins affected by two inhibitors. $\beta$-actin was used as the protein loading control. (C) Decrease in the apoptotic AGS cells characterized by TUNEL and DAPI staining assays. TUNEL and DAPI staining showed decreases in the 13-AC-induced apoptotic characteristics when treated with SB203580 and SP600125. Scale bars $=50 \mu \mathrm{m}$.

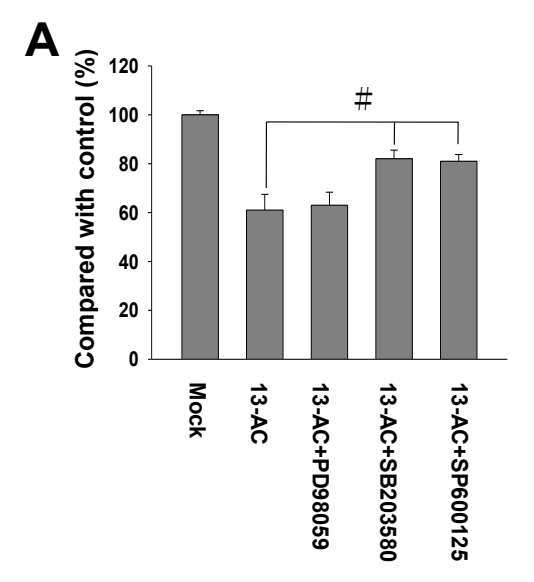

B
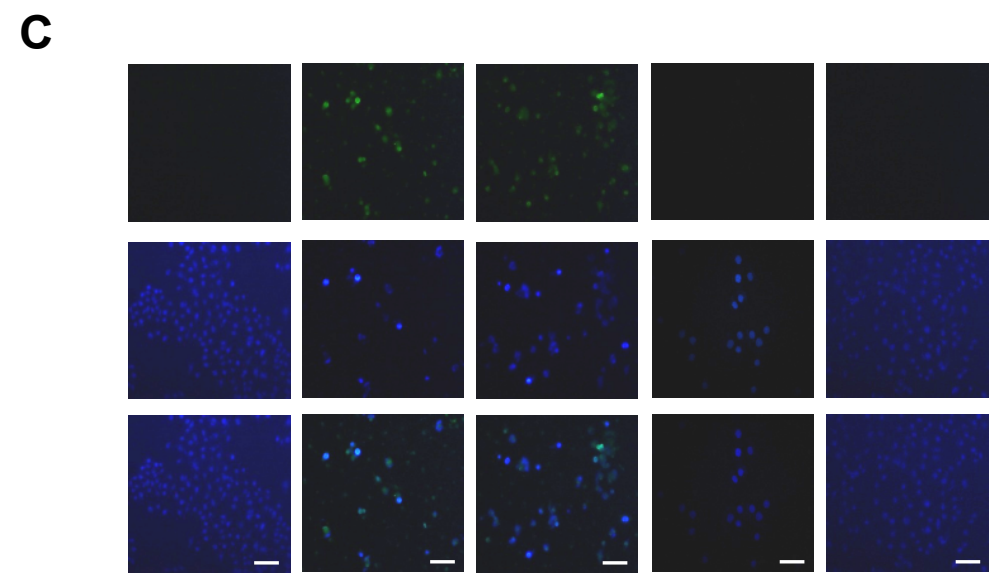

Mock

13-AC
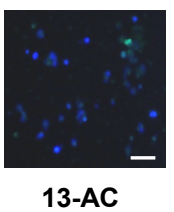

$(15 \mu \mathrm{M})$

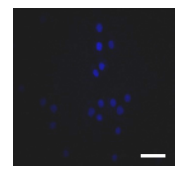

13-AC

$(15 \mu \mathrm{M})$

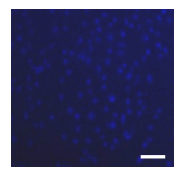

13-AC

$(15 \mu \mathrm{M})$

+PD98059

+SB203580

+SP600125

\subsection{Inhibition of $p 38$ and JNK Activities Rescued the Cell Cytotoxicity of AGS Cells by 13-AC}

To further explore whether 13-AC-induced apoptosis is mediated through the MAPKs pathways, three different inhibitors (PD98059, SB03580 and SP600125) were added to elucidate the MAPKs-activated cell apoptosis upon 13-AC treatment. As shown in Figure 6A, an increasing cell viability was observed $(60 \%-80 \%)$ upon treatment with SB203580 as well as similar effects of SP600125 at the concentration of $15 \mu \mathrm{M}$ in 13-AC-treated AGS cells. In contrast, the cell viability of 13-AC-treated AGS cells was not increased after pre-treatment with PD98059 (a MEK-specific 
inhibitor). As SB203580 is a p38-specific inhibitor and SP600125 is a JNK-specific inhibitor, we concluded that 13-AC induced cell apoptosis in AGS cells through the p38 and JNK signaling pathways. Furthermore, the expression levels of Bcl-2, Bcl-xl and Mcl-1 proteins were increased, while on the other hand, the expression levels of Bax and Bad proteins were decreased in 13-AC-treated cells when the cells were pretreated with SB203580 and SP600125 (Figure 6B). In addition, TUNEL and DAPI assays were performed to detect DNA fragmentation after 13-AC-induced apoptosis. Positively TUNEL- and DAPI-stained AGS cells after 13-AC treatment are shown in Figure 6C. Upon pre-treatment with SB203580 or SP600125, the amount of positively TUNEL- and DAPI-stained AGS cells was significantly decreased in comparison with the negative control, which was 13-AC-treated AGS cells (Figure 6C). Altogether, these results indicated that the p38 and JNK pathways are partially involved in the 13-AC-induced apoptosis of AGS cells.

\section{Discussion}

The current study demonstrated that the anti-cancer effect of 13-AC is related to its cell cytotoxic effects, and apoptosis is induced in AGS cells. 13-AC treatment clearly reduced the cell viability of AGS cells in a dose-dependent manner, as shown by MTT assay. Besides, colony formation assays and wound-healing assays were employed for identification of the cytotoxic effects of 13-AC on AGS cells (Figure 1). The apoptotic morphological characteristics of AGS cells induced by 13-AC were also observed by TUNEL/DAPI staining and Annexin V/PI staining assays using flow cytometry, which showed that both early and late apoptosis occurred upon 13-AC treatment (Figure 2).

\subsection{3-AC Induces Apoptosis and Causes Mitochondria Dysfunction in AGS Cells}

There is growing interest in cell biology in terms of evaluating changes in the mitochondrial membrane potential so as to define the role in initiating apoptosis and the cell cycle. In this study, the mitochondrial membrane potential $(\Delta \Psi \mathrm{m})$ was assessed using JC-1 dye. 13-AC-treated AGS cells showed a significant reduction in red fluorescence and increased signals in green fluorescence, suggesting a loss of mitochondrial membrane potential due to treatment with 13-AC (Figure 4A).

Bcl-2 family members regulate the mitochondrial cell death pathway [36]; in particular, the stoichiometries of Bax (pro-apoptotic member) and Bcl-2 (anti-apoptotic member) are critical for cytochrome $\mathrm{C}$ release and the following downstream caspase activation [37-39]. In this study, we comprehensively investigated the differentiated expression levels of several mitochondrial-related apoptosis proteins, including Bcl-2, Bcl-xl, Mcl-1, Bad, p-Bad, Bax and cytosolic cytochrome C, to explore the potential mechanisms of 13-AC-induced apoptosis through mitochondria-dependent pathways. The results are shown in Figure 4B. The expression levels of Bax, Bad and cytosolic cytochrome $\mathrm{C}$ were increased in time- and dose-dependent manners following 13-AC treatment. In contrast, the expression levels of Bcl-2, Bcl-xl, Mcl-1 and p-Bad were decreased upon 13-AC treatment. These results showed that 13-AC treatment induced cell apoptosis through activation of pro-apoptotic Bax and Bad and suppression of anti-apoptotic proteins such as Bcl-2 and Bcl-xl, which have been reported to regulate cytochrome $\mathrm{C}$ release from mitochondria.

Here, we demonstrated that the mitochondrial membrane potential in AGS cells was attenuated upon 13-AC treatment (Figure 5). These results are rationally linked with the western blotting data of 
these mitochondrial apoptotic events, such as inhibition of Bcl-2, Bcl-xl, Mcl-1, and p-Bad expressions and simultaneous enhancement of Bax and Bad expressions. Subsequently, Bax inserts into the mitochondria outer membrane and releases cytochrome $\mathrm{C}$ from mitochondrial inter-membrane spaces. Then, caspase-9 is activated, further activating the downstream effector caspase- 3 in order to cleave poly (ADP-ribose) polymerase-1 (PARP-1), which is further activated.

Activation of both caspase- 3 and caspase-9 are believed as toward mitochondrial apoptosis signals [40]. It is also well-known that the caspases are proteolytic activation during apoptosis. Upon receiving proapoptotic signals, the activation of caspase- 3 requires the activation of initiator caspases, such as caspase- 8 or caspase-9 [41]. In this study, we investigated the changes in the expression levels of caspase-3 and caspase-9 upon 13-AC treatment in AGS cells. The western blotting data showed that both cleaved-caspase-3 and cleaved-caspase-9 were up-regulated in 13-AC-treated cells (Figure 5). Similarly, the cleaved form of PARP-1 (with a molecular size of $89 \mathrm{kDa}$ ) was elevated upon 13-AC treatment. This observation is consistent with a report showing that PARP-1 is cleaved by caspase during apoptosis [33]. Furthermore, two caspase inhibitors, Z-VAD-FMK and Z-DEVD-FMK, were added simultaneously with treatment with 13-AC in AGS cells. As per the results shown, both caspase inhibitors elevated the cell viability and inhibited the 13-AC-induced cell cytotoxicity (Figure 5B). Taken together, these results revealed that the mitochondrial-dependent apoptosis pathway and activation of caspase are involved in 13-AC-induced cell apoptosis. Interestingly, these findings are similar to the possible mechanisms of apoptosis induction by another compound extracted from soft coral, 11-dehydrosinulariolide, in oral carcinoma cells and sinularin in melanoma cells, as described in our previous studies $[18,42]$.

\subsection{The MAPK Signaling Pathways are Involved in 13-AC-Induced Apoptosis}

It is well-known that mitogen-activated protein kinases (MAPKs) signaling pathways regulate cell proliferation, differentiation and apoptotic cell death in response to a variety of stresses or stimuli $[43,44]$. The three well-characterized subfamilies of MAPKs are extracellular signal regulated kinase 1 and 2 (ERK1/2), c-Jun NH2-terminal kinase (JNK) and p38 [45]. In this study, phosphorylated p38 and JNK were significantly activated, but phosphorylatedERK1/2 was down-regulated upon 13-AC treatment. The expression levels of non-phosphorylated ERK1/2, p38 and JNK did not change in comparison with DMSO-treated cells (Figure 6).

The p38 and JNK pathways are activated in response to various chemicals and stresses [46]. Initiation of the p38 and JNK pathways is required for induction of cellular apoptotic pathways, as shown in several studies $[47,48]$. Chemical stress-induced p38 and JNK activation was shown to regulate the cell cycle and cell apoptosis through modulation of the p53 tumor suppressor protein [49-51]. The p53 protein was decreased pro-survival Bcl-2 proteins and elevated pro-apoptosis Bax protein expression [52,53]. The ATF2 protein was phosphorylated either by p38 or JNK [54]. As shown in Figure 6, the expression levels of p53 and phosphorylated ATF2 were increased upon 13-AC treatment. Therefore, our results suggested that $\mathrm{p} 38$ and $\mathrm{JNK}$ signaling, at least partially, is responsible for 13-AC-induced apoptosis of AGS cells.

It is well-known that ERK1/2 plays a crucial role in mediating different cell functions, such as cell survival, cell cycle progression, apoptosis and autophagy. Phosphorylated ERK1/2 resulted in nuclear 
translocation and activation of substrates, promoting cell proliferation and inhibiting proapoptotic signals [55]. Many studies have shown that ERK1/2 has effects of the proliferation and protection of cells exposed to oxidative stress [56]. In this study, 13-AC significantly reduced phosphorylated ERK1/2 in AGS cells. Additionally, inhibition of ERK1/2 activation downregulated the expressions of Bcl-2 and Bcl-xl [57], and ERK1/2/Bcl-2 signaling is believed to be a potential therapeutic target for cancer cells [58]. 13-AC-mediated gastric carcinoma cell apoptosis was closely associated with down-regulation of the ERK1/2 signaling pathway.

The phosphatidylinositol 3-kinase/protein kinase-B (PI3K/AKT) cell signaling cascade is one of the most important intracellular pathways and is frequently activated in diverse cancers, regulating cell proliferation, cell differentiation, cellular apoptosis and cancer cell survival [59]. AKT is an important part of PI3K signaling. The activation of AKT is caused by PI3K- and PDK1-mediated phosphorylation in the catalytic domain at threonine 308. AKT regulates downstream targets in the PI3K pathway, such as TSC2, and outside of the PI3K pathway, such as Bcl-2-associated proteins and glycogen synthase kinase-3B [60].

Many studies have indicated that downregulation of the PI3K/AKT signaling pathway induces cell apoptosis [61,62]. The expression levels of phosphorylated PI3K and AKT were decreased after 13-AC treatment. Therefore, our results suggested, at least partially, that 13-AC induced apoptosis of AGS cells through downregulation of PI3K/AKT signaling.

\section{Materials and Methods}

\subsection{Materials}

13-AC was extracted from cultured Formosa soft coral Sarcophytoncrassocaule following the protocol described elsewhere [63] and dissolved in DMSO. A mitochondria/cytosol fractionation kit was obtained from BioSource International (Camarillo, CA, USA). Chemiluminescent HRP substrate was purchased from Pierce (Rockford, IL, USA). An annexin V-FITC Apoptosis Detection kit was obtained from Pharmingen (San Diego, CA, USA). A JC-1 (5,5,6,6-tetrachloro-1,1,3,3-tetraethyl benzimidazolcarbocyanine iodide) fluorescent kit was obtained from Biotium (Hayward, CA, USA). A DeadEnd $^{\mathrm{TM}}$ Fluorometric TUNEL fluorescent kit and a 4'-6-diamidino-2-phenylindole (DAPI) fluorescent kit were obtained from Promega (Madison, WI, USA). 3-(4,5-Dimethylthiazol-2-yl)-2, 5-diphenyltetrazolium bromide (MTT), dimethyl sulfoxide (DMSO), cyclosporine A (CyA), aristolochic acid (ArA), trifluoperazine (TFZ), Z-DEVD-FMK (caspase-3 inhibitor), Z-LEHD-FMK (caspase-9 inhibitor), protease inhibitor cocktail and rabbit anti-human $\beta$-actin antibodies were obtained from Sigma (St Louis, MO, USA). Goat anti-rabbit and horseradish peroxidase conjugated IgG and PVDF (polyvinylidenedifluoride) membranes were obtained from Millipore (Bellerica, MA, USA).

\subsection{Cell Culture and 13-AC Treatment}

AGS gastric carcinoma cells were obtained from the Bioresource Collection and Research Center (CBC, Food Industry Research and Development Institute, Hsinchu, Taiwan). Cells were cultured as described in our previous study [64]. AGS cells were maintained in F-12K media supplemented with $10 \% \mathrm{FBS}, 100 \mathrm{U} / \mathrm{mL}$ penicillin and $100 \mu \mathrm{g} / \mathrm{mL}$ streptomycin in a humidified incubator with $5 \% \mathrm{CO}_{2}$ 
and $95 \%$ air at $37{ }^{\circ} \mathrm{C}$. Dimethylsulfoxide (DMSO) was used to dissolve 13-AC. AGS cells were treated with different concentrations of 13-AC $(0,2.5,5,10,15$ and $20 \mu \mathrm{M})$ and harvested after incubation for $24 \mathrm{~h}$. All the experiments were repeated three times.

\subsection{MTT Assay for Cellular Cytotoxicity}

The cytotoxic effect of 13-AC on AGS cells was measured by MTT proliferation assay according to a previous report [19]. AGS cells were seeded at $1 \times 10^{4}$ per well in 96-well plates before treatment with various concentrations of 13-AC. The cells were treated with various concentrations of 13-AC $(0,2.5,5,10,15$ and $20 \mu \mathrm{M})$ in $200 \mu \mathrm{L}$ of serum complete media. After $24 \mathrm{~h}$ of treatment, MTT solution $\left(1 \mathrm{mg} / \mathrm{mL}\right.$ in PBS) was added to each well. The plates were then incubated at $37{ }^{\circ} \mathrm{C}$ for $4 \mathrm{~h}$, and reduced purple-blue MTT formazan crystals were solubilized by adding $200 \mu \mathrm{L}$ of DMSO to each well. The absorbance was measured at $595 \mathrm{~nm}$ using a microplate ELISA reader, with DMSO used as the blank.

\subsection{Wound-Healing Assay}

The anti-migratory effects of 13-AC on AGS cells were examined by a wound-healing assay according to a previous report [42,65]. AGS cells were seeded in 6-well plates. After the AGS cells grew to confluence, an artificial scratch was made with a tip in each of the wells. Cells were washed with PBS and refreshed with FBS-containing medium. Images of the experimental groups $(0,5,10$ and $15 \mu \mathrm{M} 13-\mathrm{AC})$ were acquired at $0,6,12$ and $24 \mathrm{~h}$ after treatment with 13-AC.

\subsection{Colony Formation Assay}

The colony formation assay was performed according to a previous report [66]. AGS cells were seeded in 24-well plates at a density of 2000 cells/well. After incubation for $24 \mathrm{~h}$, cells were treated with various concentrations $(0,5,10,15$ and $20 \mu \mathrm{M})$ of $13-\mathrm{AC}$ in $2 \mathrm{ml}$ of serum complete media. After incubation for 10 days, the colonies were washed with PBS and fixed with methanol for 15 min and stained with $0.15 \%$ crystal violet. The colonies were counted and scanned with a high-resolution scanner Scan Maker 9800XL (MiCROTEK, Hsinchu, Taiwain).

\subsection{Antibody and Western Blot Analyses}

Rabbit anti-human Bax, ERK, JNK and p-JNK antibodies were obtained from ProteinTech Group (Chicago, IL, USA). Rabbit anti-human antibodies against p-PI3K, AKT, p-AKT, PARP, pro-caspase-3, cleaved-caspase-3, pro-caspase-9, cleaved-caspase-9, Bcl-xl, Bcl-2, Mcl-1, Bad, p38, p-p38, p-ERK, p-ATF2 and p53 were obtained from Cell Signaling Technology (Danvers, MA, USA). Rabbit anti-human antibodies against $\mathrm{p}$-Bad and cytochrome $\mathrm{C}$ were obtained from Epitomics (Burlingame, CA, USA). Rabbit anti-human $\beta$-actin antibodies were obtained from Sigma (St Louis, MO, USA). Goat anti-rabbit and horseradish peroxidase conjugated IgG was obtained from Millipore (Bellerica, MA, USA). Immunoblotting was performed as previously described [19]. The treated samples and the control samples $(25 \mu \mathrm{g})$ were separated by $12.5 \%$ SDS-polyacrylamide gel electrophoresis (SDS-PAGE). The proteins on the gel were then transferred to PVDF membranes. The 
PVDF membranes were incubated with the primary antibody (1:1000 dilutions in 2\% dehydrated skim milk) at $4{ }^{\circ} \mathrm{C}$ overnight. Then, incubation at $4{ }^{\circ} \mathrm{C}$ was performed for $2 \mathrm{~h}$ with the secondary antibodies (goat anti-rabbit or goat anti-mouse and horseradish peroxidase conjugate, 1:5000 dilution in 2\% dehydrated skim milk). The blots were detected through chemiluminescence using enhanced ECL western blotting kit.

\subsection{Annexin V-FITC Apoptosis Assay}

Cell apoptosis was measured by Annexin/PI double staining as previously reported [67]. A total of $1 \times 10^{6}$ cells were seeded onto 5-cm Petri dishes and treated with $0.1 \% \mathrm{DMSO}$ as the vehicle or 10 and $15 \mu \mathrm{M}$ of 13 -AC for $24 \mathrm{~h}$. The cells were subsequently collected and fixed in $70 \%$ cold ethanol at $4{ }^{\circ} \mathrm{C}$ overnight. The cells were then stained with $10 \mu \mathrm{g} / \mathrm{mL}$ Annexin V-FITC and $5 \mu \mathrm{g} / \mathrm{mL}$ propidium iodide (PI) for $30 \mathrm{~min}$ at $37{ }^{\circ} \mathrm{C}$. A FACSCalibur flow cytometer and Cell-Quest software (Becton-Dickinson, Mansfield, MA, USA) were used to analyze the apoptotic cells.

\subsection{Immunofluorescence Microscopy}

AGS cells $\left(1 \times 10^{5}\right.$ cells/well $)$ cultured in 12-well plates were pretreated with 0,10 and $15 \mu \mathrm{M}$ 13-AC for $24 \mathrm{~h}$. Then, the Annexin V-FITC Apoptosis staining reagent was added to the cells according to manufacturer's protocol and incubated for $15 \mathrm{~min}$, then observed under fluorescence microscopy (Olympus IX71 CTS, Chinetek Scientific, Hong Kong, China). The DeadEnd ${ }^{\mathrm{TM}}$ Fluorometric TUNEL System (Promega, Madison, WI, USA) was used to detect nuclear DNA fragmentation according to the manufacturer's manual. The fluorescein-12-dUTP-labeled DNA can then be visualized directly under fluorescence microscopy (Olympus IX71 CTS, Chinetekcientific, Hong Kong, China). The cells were photographed. A fluorescence microscope was also used to identify the condense nuclei and DNA chromatin fragmented that were stained with DAPI [29].

\subsection{Mitochondrial Membrane Potential ( $(\Psi m)$ Assay Using Fluorescence Microscopy}

Changes in the mitochondrial membrane potential $(\Delta \Psi \mathrm{m})$ after treatment with different concentrations of 13-AC were examined by staining with JC-1 (5,5,6,6-tetrachloro-1,1,3,3-tetraethylben zimidazolcarbocyanine iodide) dye (Biotium, Hayward, CA, USA). AGS cells were pretreated with 13-AC and incubated with $10 \mathrm{mg} / \mathrm{mL} \mathrm{JC}-1$ at $37^{\circ} \mathrm{C}$ for $30 \mathrm{~min}$ in the dark. Cells were washed twice with PBS and observed under fluorescence microscopy (Olympus IX71 CTS, Chinetek Scientific, Hong Kong, China).

\subsection{Inhibitors Assessment}

To further determine the effects of p38, ERK, and JNK on 13-AC-induced cell proliferation arrest, a total of $1 \times 10^{5}$ cells seeded in a 24-well plate were pre-incubated for $2 \mathrm{~h}$ with specific inhibitors for p38 (SB239063), ERK (PD98059), and JNK (SP600125) prior to 13-AC administration. Afterwards, the cell viability rate was determined by MTT assay. 


\subsection{Statistical Analysis}

The results of the MTT assay, colony formation assay, cell cycle distribution analysis, caspase-3 activity and caspase-9 activity were analyzed by Student's test. $p<0.05$ was considered statistically significant.

\section{Conclusion}

In conclusion, our study results suggest that 13-AC induces apoptosis through the activation of $\mathrm{p} 38$ and JNK and suppression of PI3K/AKT so as to affect the expression levels of mitochondrial apoptotic proteins. Therefore, the results may provide potential pharmacological evidence that 13-AC possesses anti-gastric carcinoma effects, and may be employed as a potential chemotherapeutic agent.

\section{Acknowledgements}

This work was supported in part by grants from the National Science Council (NSC 101-2313-B-276-002 and NSC 102-2313-B-276-002-MY3) to YJ Wu and Chang Gung Memorial Hospital Research Fund (CMRPD1A0553 and CMRPD1C0821) to RY Wang. The authors also thank Ann Na Gong for English editing.

\section{Conflict of Interests}

The authors declare that there are no conflicts of interest regarding the publication of this paper.

\section{References}

1. Hu, Y.; Fang, J.Y.; Xiao, S.D. Can the incidence of gastric cancer be reduced in the new century? J. Dig. Dis. 2013, 14, 11-15.

2. Thiel, A.; Ristimaki, A. Gastric cancer: Basic aspects. Helicobacter 2012, 17 (Suppl. 1), $26-29$.

3. Ferlay, J.; Shin, H.R.; Bray, F.; Forman, D.; Mathers, C.; Parkin, D.M. Estimates of worldwide burden of cancer in 2008: Globocan 2008. Int. J. Cancer 2010, 127, 2893-2917.

4. Truong Minh, P.; Fujino, Y.; Yoshimura, T.; Tokui, N.; Mizoue, T.; Yatsuya, H.; Toyoshima, H.; Sakata, K.; Kikuchi, S.; Hoshiyama, Y.; et al. Mortality and incidence rates of stomach cancer in the jacc study. J. Epidemiol. 2005, 15 (Suppl. 2), S89-S97.

5. Yamashita, K.; Sakuramoto, S.; Nemoto, M.; Shibata, T.; Mieno, H.; Katada, N.; Kikuchi, S.; Watanabe, M. Trend in gastric cancer: 35 years of surgical experience in japan. World J. Gastroenterol. 2011, 17, 3390-3397.

6. Meyer, H.J.; Wilke, H. Treatment strategies in gastric cancer. Deutsches Arzteblatt Int. 2011, 108, 698-705.

7. Proserpio, I.; Rausei, S.; Barzaghi, S.; Frattini, F.; Galli, F.; Iovino, D.; Rovera, F.; Boni, L.; Dionigi, G.; Pinotti, G. Multimodal treatment of gastric cancer. World J. Gastrointest. Surg. 2014, 6, 55-58.

8. Lin, Y.S.; Chen, M.J.; Shih, S.C.; Bair, M.J.; Fang, C.J.; Wang, H.Y. Management of infection after gastric surgery. World J. Gastroenterol. 2014, 20, 5274-5282. 
9. Montori, G.; Coccolini, F.; Ceresoli, M.; Catena, F.; Colaianni, N.; Poletti, E.; Ansaloni, L. The treatment of peritoneal carcinomatosis in advanced gastric cancer: State of the art. Int. J. Surg. Oncol. 2014, 2014, 912418.

10. Zhang, X.; Yashiro, M.; Ren, J.; Hirakawa, K. Histone deacetylase inhibitor, trichostatin a, increases the chemosensitivity of anticancer drugs in gastric cancer cell lines. Oncol. Rep. 2006, 16, 563-568.

11. Faulkner, D.J. Marine natural products. Nat. Prod. Rep. 2001, 18, 1-49.

12. Faulkner, D.J. Marine natural products. Nat. Prod. Rep. 2002, 19, 1-48.

13. Ojika, M.; Islam, M.K.; Shintani, T.; Zhang, Y.; Okamoto, T.; Sakagami, Y. Three new cytotoxic acylspermidines from the soft coral, Sinularia sp. Biosci. Biotechnol. Biochem. 2003, 67, 1410-1412.

14. Poza, J.J.; Fernandez, R.; Reyes, F.; Rodriguez, J.; Jimenez, C. Isolation, biological significance, synthesis, and cytotoxic evaluation of new natural parathiosteroids a-c and analogues from the soft coral Paragorgia sp. J. Org. Chem. 2008, 73, 7978-7984.

15. Chiang, P.C.; Chien, C.L.; Pan, S.L.; Chen, W.P.; Teng, C.M.; Shen, Y.C.; Guh, J.H. Induction of endoplasmic reticulum stress and apoptosis by a marine prostanoid in human hepatocellular carcinoma. J. Hepatol. 2005, 43, 679-686.

16. Kamel, H.N.; Ferreira, D.; Garcia-Fernandez, L.F.; Slattery, M. Cytotoxic diterpenoids from the hybrid soft coral Sinularia maxima x Sinularia polydactyla. J. Nat. Prod. 2007, 70, 1223-1227.

17. Hassan, H.M.; Khanfar, M.A.; Elnagar, A.Y.; Mohammed, R.; Shaala, L.A.; Youssef, D.T.A.; Hifnawy, M.S.; El Sayed, K.A. Pachycladins A-E, prostate cancer invasion and migration inhibitory eunicellin-based diterpenoids from the red sea soft coral Cladiella pachyclados. J. Nat. Prod. 2010, 73, 848-853.

18. Liu, C.I.; Chen, C.C.; Chen, J.C.; Su, J.H.; Huang, H.H.; Chen, J.Y.; Wu, Y.J. Proteomic analysis of anti-tumor effects of 11-dehydrosinulariolide on cal-27 cells. Mar. Drugs 2011, 9, 1254-1272.

19. Su, C.C.; Su, J.H.; Lin, J.J.; Chen, C.C.; Hwang, W.I.; Huang, H.H.; Wu, Y.J. An investigation into the cytotoxic effects of 13-acetoxysarcocrassolide from the soft coral Sarcophyton crassocaule on bladder cancer cells. Mar. Drugs 2011, 9, 2622-2642.

20. Neoh, C.A.; Wang, R.Y.; Din, Z.H.; Su, J.H.; Chen, Y.K.; Tsai, F.J.; Weng, S.H.; Wu, Y.J. Induction of apoptosis by sinulariolide from soft coral through mitochondrial-related and p38mapk pathways on human bladder carcinoma cells. Mar. Drugs 2012, 10, 2893-2911.

21. Lowe, S.W.; Lin, A.W. Apoptosis in cancer. Carcinogenesis 2000, 21, 485-495.

22. Denicourt, C.; Dowdy, S.F. Targeting apoptotic pathways in cancer cells. Science 2004, 305, 1411-1413.

23. Liao, P.C.; Tan, S.K.; Lieu, C.H.; Jung, H.K. Involvement of endoplasmic reticulum in paclitaxel-induced apoptosis. J. Cell. Biochem. 2008, 104, 1509-1523.

24. Yokouchi, M.; Hiramatsu, N.; Hayakawa, K.; Kasai, A.; Takano, Y.; Yao, J.; Kitamura, M. Atypical, bidirectional regulation of cadmium-induced apoptosis via distinct signaling of unfolded protein response. Cell Death Differ. 2007, 14, 1467-1474.

25. Green, D.R.; Reed, J.C. Mitochondria and apoptosis. Science 1998, 281, 1309-1312.

26. Nicholson, D.W.; Thornberry, N.A. Life and death decisions. Science 2003, 299, 214-215.

27. Rao, R.; Ellerby, H.; Bredesen, D. Coupling endoplasmic reticulum stress to the cell death program. Cell Death Differ. 2004, 11, 372-380. 
28. Boyce, M.; Yuan, J. Cellular response to endoplasmic reticulum stress: A matter of life or death. Cell Death Differ. 2006, 13, 363-373.

29. Liu, C.I.; Wang, R.Y.; Lin, J.J.; Su, J.H.; Chiu, C.C.; Chen, J.C.; Chen, J.Y.; Wu, Y.J. Proteomic profiling of the 11-dehydrosinulariolide-treated oral carcinoma cells ca9-22: Effects on the cell apoptosis through mitochondrial-related and er stress pathway. J. Proteomics 2012, 75, 5578-5589.

30. Moenner, M.; Pluquet, O.; Bouchecareilh, M.; Chevet, E. Integrated endoplasmic reticulum stress responses in cancer. Cancer Res. 2007, 67, 10631-10634.

31. Xu, C.; Bailly-Maitre, B.; Reed, J.C. Endoplasmic reticulum stress: Cell life and death decisions. J. Clin. Invest. 2005, 115, 2656-2664.

32. Nicholson, K.M.; Quinn, D.M.; Kellett, G.L.; Warr, J.R. Ly294002, an inhibitor of phosphatidylinositol-3-kinase, causes preferential induction of apoptosis in human multidrug resistant cells. Cancer Lett. 2003, 190, 31-36.

33. Affar, E.B.; Germain, M.; Winstall, E.; Vodenicharov, M.; Shah, R.G.; Salvesen, G.S.; Poirier, G.G. Caspase-3-mediated processing of poly(adp-ribose) glycohydrolase during apoptosis. J. Biol. Chem. 2001, 276, 2935-2942.

34. Miloso, M.; Scuteri, A.; Foudah, D.; Tredici, G. Mapks as mediators of cell fate determination: An approach to neurodegenerative diseases. Curr. Med. Chem. 2008, 15, 538-548.

35. Suganuma, T.; Workman, J.L. Map kinases and histone modification. J. Mol. Cell Biol. 2012, 4, $348-350$.

36. Leanza, L.; Henry, B.; Sassi, N.; Zoratti, M.; Chandy, K.G.; Gulbins, E.; Szabo, I. Inhibitors of mitochondrial kv1.3 channels induce bax/bak-independent death of cancer cells. EMBO Mol. Med. 2012, 4, 577-593.

37. Ribe, E.M.; Serrano-Saiz, E.; Akpan, N.; Troy, C.M. Mechanisms of neuronal death in disease: Defining the models and the players. Biochem. J. 2008, 415, 165-182.

38. Shankar, S.; Srivastava, R.K. Bax and bak genes are essential for maximum apoptotic response by curcumin, a polyphenolic compound and cancer chemopreventive agent derived from turmeric, curcuma longa. Carcinogenesis 2007, 28, 1277-1286.

39. Zhou, J.; Zhang, S.; Ong, C.N.; Shen, H.M. Critical role of pro-apoptotic bcl-2 family members in andrographolide-induced apoptosis in human cancer cells. Biochem. Pharmacol. 2006, 72, 132-144.

40. Wang, H.L.; Yeh, T.H.; Chou, A.H.; Kuo, Y.L.; Luo, L.J.; He, C.Y.; Huang, P.C.; Li, A.H. Polyglutamine-expanded ataxin-7 activates mitochondrial apoptotic pathway of cerebellar neurons by upregulating bax and downregulating bcl-x(1). Cell. Signal. 2006, 18, 541-552.

41. Ola, M.S.; Nawaz, M.; Ahsan, H. Role of bcl-2 family proteins and caspases in the regulation of apoptosis. Mol. Cell. Biochem. 2011, 351, 41-58.

42. Su, T.R.; Lin, J.J.; Chiu, C.C.; Chen, J.Y.; Su, J.H.; Cheng, Z.J.; Hwang, W.I.; Huang, H.H.; Wu, Y.J. Proteomic investigation of anti-tumor activities exerted by sinularin against a2058 melanoma cells. Electrophoresis 2012, 33, 1139-1152.

43. Chang, L.; Karin, M. Mammalian map kinase signalling cascades. Nature 2001, 410, 37-40.

44. Santarpia, L.; Lippman, S.M.; El-Naggar, A.K. Targeting the mapk-ras-raf signaling pathway in cancer therapy. Expert Opin. Ther. Targets 2012, 16, 103-119. 
45. Boronkai, A.; Brubel, R.; Racz, B.; Tamas, A.; Kiss, P.; Horvath, G.; Lubics, A.; Szigeti, A.; Bellyei, S.; Toth, G.; et al. Effects of pituitary adenylate cyclase activating polypeptide on the survival and signal transduction pathways in human choriocarcinoma cells. Ann. N. Y. Acad. Sci. 2009, 1163, 353-357.

46. Coulthard, L.R.; White, D.E.; Jones, D.L.; McDermott, M.F.; Burchill, S.A. P38(mapk): Stress responses from molecular mechanisms to therapeutics. Trends Mol. Med. 2009, 15, 369-379.

47. Yanase, S.; Yasuda, K.; Ishii, N. Adaptive responses to oxidative damage in three mutants of caenorhabditis elegans (age-1, mev-1 and daf-16) that affect life span. Mech. Ageing Dev. 2002, 123, 1579-1587.

48. Wang, D.; Lu, J.; Liu, Y.; Meng, Q.; Xie, J.; Wang, Z.; Teng, L. Liquiritigenin induces tumor cell death through mitogen-activated protein kinase- (mpaks-) mediated pathway in hepatocellular carcinoma cells. BioMed. Res. Int. 2014, 2014, 965316.

49. Lv, C.; Hong, Y.; Miao, L.; Li, C.; Xu, G.; Wei, S.; Wang, B.; Huang, C.; Jiao, B. Wentilactone a as a novel potential antitumor agent induces apoptosis and $\mathrm{g} 2 / \mathrm{m}$ arrest of human lung carcinoma cells, and is mediated by hras-gtp accumulation to excessively activate the ras/raf/erk/p53-p21 pathway. Cell Death Dis. 2013, 4, e952.

50. Bu, H.Q.; Liu, D.L.; Wei, W.T.; Chen, L.; Huang, H.; Li, Y.; Cui, J.H. Oridonin induces apoptosis in sw1990 pancreatic cancer cells via p53- and caspase-dependent induction of p38 mapk. Oncol. Rep. 2014, 31, 975-982.

51. Yang, F.; Chen, H.; Liu, Y.; Yin, K.; Wang, Y.; Li, X.; Wang, G.; Wang, S.; Tan, X.; Xu, C.; et al. Doxorubicin caused apoptosis of mesenchymal stem cells via p38, jnk and p53 pathway. Cell. Physiol. Biochem. 2013, 32, 1072-1082.

52. Cui, L.; Deng, Y.; Rong, Y.; Lou, W.; Mao, Z.; Feng, Y.; Xie, D.; Jin, D. Irf-2 is over-expressed in pancreatic cancer and promotes the growth of pancreatic cancer cells. Tumour Biol. 2012, 33, 247-255.

53. Masmoudi-Kouki, O.; Douiri, S.; Hamdi, Y.; Kaddour, H.; Bahdoudi, S.; Vaudry, D.; Basille, M.; Leprince, J.; Fournier, A.; Vaudry, H.; et al. Pituitary adenylate cyclase-activating polypeptide protects astroglial cells against oxidative stress-induced apoptosis. J. Neurochem. 2011, 117, 403-411.

54. Makkinje, A.; Quinn, D.A.; Chen, A.; Cadilla, C.L.; Force, T.; Bonventre, J.V.; Kyriakis, J.M. Gene 33/mig-6, a transcriptionally inducible adapter protein that binds gtp-cdc42 and activates sapk/jnk. A potential marker transcript for chronic pathologic conditions, such as diabetic nephropathy. Possible role in the response to persistent stress. J. Biol. Chem. 2000, 275, 17838-17847.

55. Sweatt, J.D. The neuronal map kinase cascade: A biochemical signal integration system subserving synaptic plasticity and memory. J. Neurochem. 2001, 76, 1-10.

56. Shen, H.; Liu, J.; Wang, Y.; Lian, H.; Wang, J.; Xing, L.; Yan, X.; Wang, J.; Zhang, X. Aflatoxin g1-induced oxidative stress causes DNA damage and triggers apoptosis through mapk signaling pathway in a549 cells. Food Chem. Toxicol. 2013, 62, 661-669.

57. Boucher, M.J.; Morisset, J.; Vachon, P.H.; Reed, J.C.; Laine, J.; Rivard, N. Mek/erk signaling pathway regulates the expression of bcl-2, bcl-x(1), and mcl-1 and promotes survival of human pancreatic cancer cells. J. Cell. Biochem. 2000, 79, 355-369.

58. Balmanno, K.; Cook, S.J. Tumour cell survival signalling by the erk1/2 pathway. Cell Death Differ. 2009, 16, 368-377. 
59. Janku, F.; Wheler, J.J.; Westin, S.N.; Moulder, S.L.; Naing, A.; Tsimberidou, A.M.; Fu, S.; Falchook, G.S.; Hong, D.S.; Garrido-Laguna, I.; et al. Pi3k/akt/mtor inhibitors in patients with breast and gynecologic malignancies harboring pik3ca mutations. J. Clin. Oncol. 2012, 30, 777-782.

60. Cheung, M.; Testa, J.R. Diverse mechanisms of akt pathway activation in human malignancy. Curr. Cancer Drug Targets 2013, 13, 234-244.

61. Liu, M.; Li, C.M.; Chen, Z.F.; Ji, R.; Guo, Q.H.; Li, Q.; Zhang, H.L.; Zhou, Y.N. Celecoxib regulates apoptosis and autophagy via the pi3k/akt signaling pathway in sgc-7901 gastric cancer cells. Int. J. Mol. Med. 2014, 33, 1451-1458.

62. Hong, S.W.; Shin, J.S.; Moon, J.H.; Kim, Y.S.; Lee, J.; Choi, E.K.; Ha, S.H.; Lee, D.H.; Chung, H.N.; Kim, J.E.; et al. Nvp-bez235, a dual pi3k/mtor inhibitor, induces cell death through alternate routes in prostate cancer cells depending on the pten genotype. Apoptosis 2014, 19, 895-904.

63. Duh, C.Y.; Wang, S.K.; Chung, S.G.; Chou, G.C.; Dai, C.F. Cytotoxic cembrenolides and steroids from the formosan soft coral Sarcophyton crassocaule. J. Nat. Prod. 2000, 63, 1634-1637.

64. Su, T.R.; Tsai, F.J.; Lin, J.J.; Huang, H.H.; Chiu, C.C.; Su, J.H.; Yang, Y.T.; Chen, J.Y.; Wong, B.S.; Wu, Y.J. Induction of apoptosis by 11-dehydrosinulariolide via mitochondrial dysregulation and er stress pathways in human melanoma cells. Mar. Drugs 2012, 10, 1883-1898.

65. Wang, R.Y.K.L. Host factors in the replication of positive-strand rna viruses. Chang Gung Med. J. 2012, 35, 14.

66. Chen, Y.J.; Su, J.H.; Tsao, C.Y.; Hung, C.T.; Chao, H.H.; Lin, J.J.; Liao, M.H.; Yang, Z.Y.; Huang, H.H.; Tsai, F.J.; et al. Sinulariolide induced hepatocellular carcinoma apoptosis through activation of mitochondrial-related apoptotic and perk/eif2alpha/atf4/chop pathway. Molecules 2013, 18, 10146-10161.

67. Chiu, C.C.; Haung, J.W.; Chang, F.R.; Huang, K.J.; Huang, H.M.; Huang, H.W.; Chou, C.K.; Wu, Y.C.; Chang, H.W. Golden berry-derived 4beta-hydroxywithanolide e for selectively killing oral cancer cells by generating ros, DNA damage, and apoptotic pathways. PLOS One 2013, 8, e64739.

(C) 2014 by the authors; licensee MDPI, Basel, Switzerland. This article is an open access article distributed under the terms and conditions of the Creative Commons Attribution license (http://creativecommons.org/licenses/by/4.0/). 